Al-Azhar Bull. Sci. Vol. 19, No. 1 (June.): pp. 41-48, 2008.

\title{
IONIZATION OF PERLNDOPRIL PERMADIOL AND AMINEPTINE - HCL AS PHARMACEUTICAL LIGANDS AND THEIR COMPLEXES WITH DIVALENT CATIONS AND LANTHANONS.
}

ADEL, S. ORABI ${ }^{\mathrm{A}}$, N.B. EL-ASSY ${ }^{\mathrm{B}}$, ABD EL-GWAD M. RADI ${ }^{\mathrm{C}}$, N.S. ABDELGHANY $^{\mathrm{B}}$, SAWSSAN M. ABU., EL HASSAN. ${ }^{\mathrm{B}}$

a-Department of Chemistry, Faculty of Science, Suez Canal University, Ismailia, Egypt

b- Suez Canal University, b-Department of Chemistry, Faculty of Education, El-Arish, Egypt.

c- Department of Chemistry, Faculty of Science, (Demiatta), Mansoura University, Egypt.

\section{Abstract}

Proton - constants of Per (I) and Amin (II) ligands and the formation constants of their complexes with some transition metal ions ( $\mathrm{Zn}(\mathrm{II})$ and $\mathrm{Cu}(\mathrm{II})$ ) and some trivalent lanthanides (Ce(III), $\operatorname{Pr}(\mathrm{III})$, and $\operatorname{Er}(\mathrm{III}))$ ions have been determined potentiometrically in aqueous methanol medium. The effect of temperature was studied at 20,30 , and $40^{\circ} \mathrm{C}$. The thermodynamic parameters $\left(\Delta \mathrm{H}^{\mathrm{o}}, \Delta \mathrm{G}^{\mathrm{o}}, \Delta \mathrm{S}^{\mathrm{o}}\right)$ were evaluated and discussed. The formation curves for the metal complexes were obtained and the formation constants were determined.

Key words: potentiometry, complexes; thermodynamic

\section{Experimental}

Reagents and Materials: Metal ion solutions (0.01M) were prepared from Analar metals nitrate in bidistilled water. Standardization of metal ions were performed by complexometric titration using standard solution of EDTA (1). The ligand solutions $(0.01 \mathrm{M})$ were prepared by dissolving the accurate weight of the solid in aqueous methanol medium. Solutions of $0.1 \mathrm{M} \mathrm{HCl}$ and $0.1 \mathrm{M}$ of nitric acid and potassium nitrate were prepared by dissolving A.R. grade chemicals in bidistilled water. The acids were standerdized by using primary standard base.

Potentiometric Measurements: $\mathrm{pH}$ - measurements were carried out using Fisher scientific equipment $\mathrm{pH}$ meter model $825 \mathrm{mp}$.

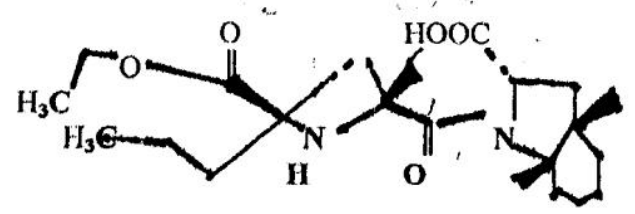

(I)

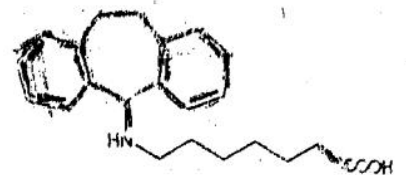

(II) 
Method of calculation: The proto-ligand stability constants were calculated using the linear least-square computer program(2).

\section{Results and Discussion}

\section{Dissociation constants of Perlndopril (Per) and Amineptine - HCl (Amin)} Ligands.

The dissociation constants of Per and Amin were determined by titrating $10 \mathrm{ml}$ of the ligand $(0.001 \mathrm{M})$ with $0.0035 \mathrm{M} \mathrm{KOH}$ at different temperatures and ionic strength 0.1 using $\mathrm{KNO}_{3}$. The pKa's values are shown in table (1).

\section{Effect of temperature:}

The effect of temperature on the ionization constants of ligands are shown in Figs.(1-2). It is clear that pKa values increase in order $20>30>40^{\circ} \mathrm{C}$ and this may be due to the fast deprotonation process at high temperature.

\section{Ionization constants and thermodynamic functions:}

The values of $\Delta \mathrm{H}^{\mathrm{o}}$ are shown in table (1) indicate that endothermic ionization process is enhanced with temperature in addition to the positive values of $\Delta \mathrm{H}^{\circ}$ and the positive values of $\Delta \mathrm{G}^{\mathrm{o}}$ making the ionization process nonspontaneous and $\Delta \mathrm{S}^{\mathrm{o}}$ values suggest solvation of the ligands in aqueous - methanol medium(3).

\section{Potentiometric studies:}

The titration curves of the metal-ligand mixtures were plotted and the $\mathrm{pH}$ reading depressed relative to that of the titration curves of the free ligand. The formation constants for (Per-Zn(II) complex) and (Per- $\mathrm{Cu}$ (II) complex) were determined by using the linear least- square computer program. According the average values are represented in table (2) the following general remarks can be pointed:

1- The maximum values of $\mathrm{n}$ was $=1$ indicating the formation of $1: 1$ (metal:ligand) complexes(4).

2- The metal titration curves indicating the large decrease in $\mathrm{pH}$ for metal titration curves relative to ligand titration curve are shown in Fig.(3).

3 - The metal ions solutions used in the present study were dilute $\left(10^{-4} \mathrm{M}\right)$, hence there were no possibility of formation of polynuclear complexes(5).

4- The formation constants of (Per-Zn (II)) complex are relative small compared with those of (Per-Cu (II)) complex where the d orbital of $\mathrm{Zn}$ (II) is fully(6). 


\section{Thermodynamic functions:}

Thermodynamic parameters $\Delta \mathrm{G}^{\mathrm{o}}, \Delta \mathrm{H}^{\mathrm{o}}$ and $\Delta \mathrm{S}^{\mathrm{o}}$ for the complexes were calculated from the stability constants obtained at various temperatures $(20,30$ and $40^{\circ} \mathrm{C}$ ). The values of the thermodynamic parameters associated with complexes formation are indicated in table (3). The stepwise stability constants of complexes increase with increasing the temperature. The positive values of $\Delta \mathrm{G}^{\mathrm{o}}$ for complexation process suggests the nonspontaneous process. It was suggested (3) that the ions in aqueous solution, order the water molecules around them and during complex formation between oppositely charged ions (ligand $-\mathrm{L}^{2-}$ and metals $\mathrm{M}^{\mathrm{n}+}$ ) will lead to the breakdown of metal-water arrangement resulting in positive entropy and enthalpy changes. Qualitativly, the data in table (3) do not agree well with this picture. The negative values of $\Delta \mathrm{H}^{\mathrm{o}}$ could be explained by the increase of solvent basicity (7) which causes exothermic behavior for the transfer of metal ion from the aqueous state to methanol solvent. The $\Delta \mathrm{H}^{\mathrm{o}}$ dependence on solvent can be ascribed primarily to different hydration-solvation condition of the metal ions (2). Such negative entropy change can be attributed to the extensive solvation of metal chelates in aqueous-methanol medium.

Table (1) Thermodynamic functions for the dissociation of Per and Amin in (1/10) of methanol : water and $0 . \mathrm{IM} \mathrm{KNO}_{3}$ at different temperatures.

\begin{tabular}{|c|c|c|c|c|c|c|c|c|}
\hline \multirow{2}{*}{$\begin{array}{c}\text { Temp. } \\
\text { K }\end{array}$} & \multicolumn{2}{|c|}{$\begin{array}{c}\text { Dissociation constant } \\
\mathrm{pK}^{\mathrm{H}}\end{array}$} & \multicolumn{2}{|c|}{$\begin{array}{c}\text { Enthalpy Chang } \\
\Delta \mathrm{H}^{\mathrm{o}}\end{array}$} & \multicolumn{2}{|c|}{$\begin{array}{l}\text { Free energy change } \\
\qquad \Delta \mathrm{G}^{\mathrm{o}}\end{array}$} & \multicolumn{2}{|c|}{$\begin{array}{c}\text { Entropy Chang } \\
\Delta \mathrm{S}^{\mathrm{o}}\end{array}$} \\
\hline & Per & Amin & Per & - Amin & Per & - Amin & Per & Amin \\
\hline 293 & 9.4593 & 5.5543 & 63.097 & 15.9674 & 12.684 & 7.4474 & 0.1720 & 29 \\
\hline 303 & 9.3021 & 5.5143 & 63.097 & 15.9674 & 12.899 & 7.6485 & 0.16567 & 27 \\
\hline 313 & 9.145 & 5.4793 & 63.097 & 15.9674 & 13.099 & 7.848 & 0.1597 & 25 \\
\hline
\end{tabular}

$\Delta \mathrm{G}^{\mathrm{o}}$ units are $\left(\mathrm{kcal} . \mathrm{mol}^{-1}\right)$.

$\Delta \mathrm{H}^{\mathrm{o}}$ units are $\left(\mathrm{kcal} . \mathrm{mol}^{-1}\right)$.

$\Delta \mathrm{S}^{\mathrm{o}}$ units are (cal. $\left.\mathrm{mol}^{-1} \cdot \mathrm{K}^{-1}\right)$.

Table (2) Stepwise stability constants for the complexation of Per with $\mathrm{Cu}^{2+}$, and $\mathrm{Zn}^{2+}$ in (1/10) methanol-water medium and $0.1 \mathrm{M} \mathrm{KNO}_{3}$ at different temperatures.

\begin{tabular}{|c|c|c|c|}
\hline M & $\begin{array}{c}293 K \\
\log K f\end{array}$ & $\begin{array}{c}303 \mathrm{~K} \\
\log \mathrm{Kf}\end{array}$ & $\begin{array}{c}313 \mathrm{~K} \\
\log \mathrm{Kf}\end{array}$ \\
\hline $\mathrm{Cu}(\mathrm{II})$ & 5.1264 & 5.154 & 5.3004 \\
\hline $\mathrm{Zn}(\mathrm{II})$ & 3.608 & 3.6764 & 3.784 \\
\hline
\end{tabular}



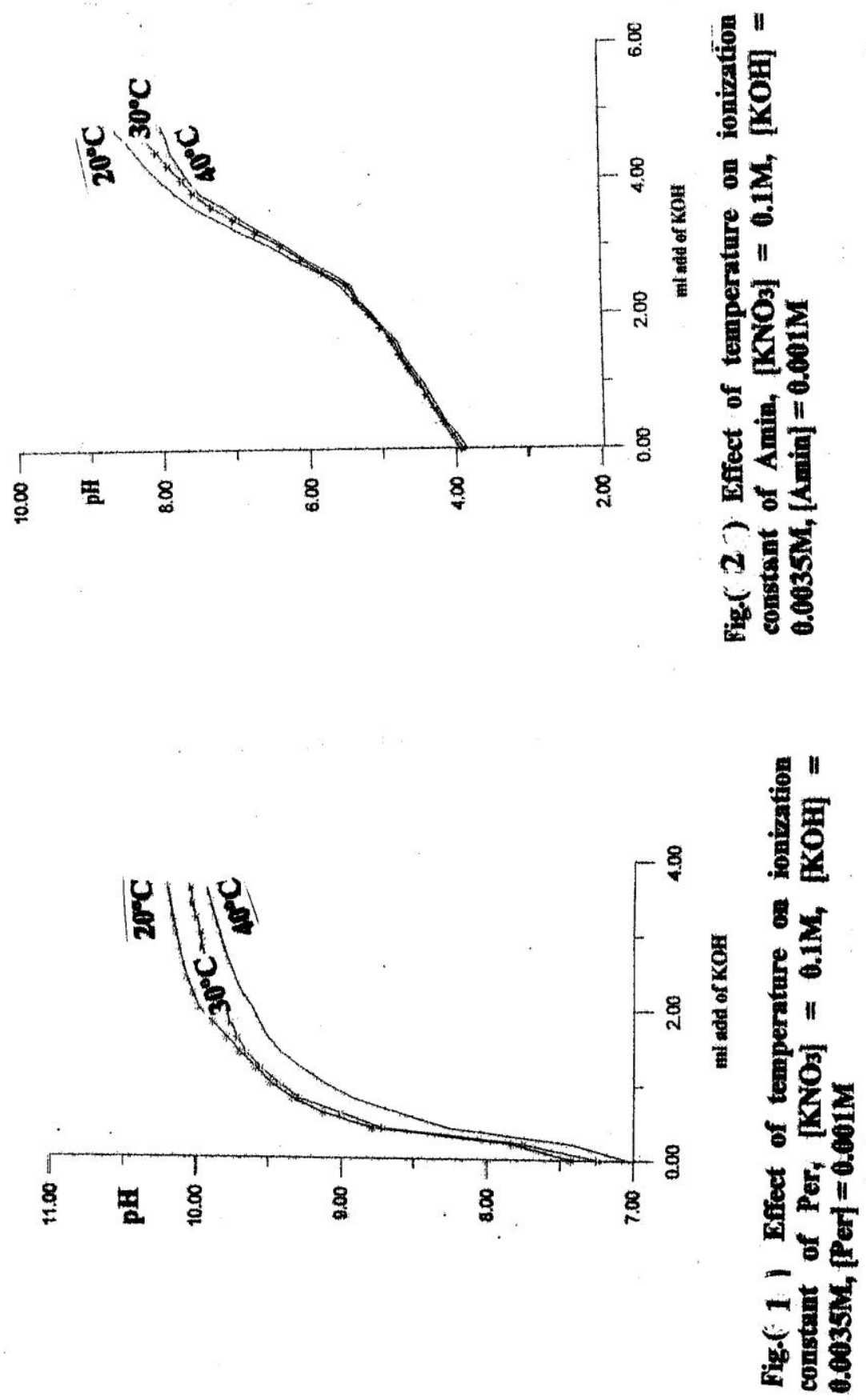


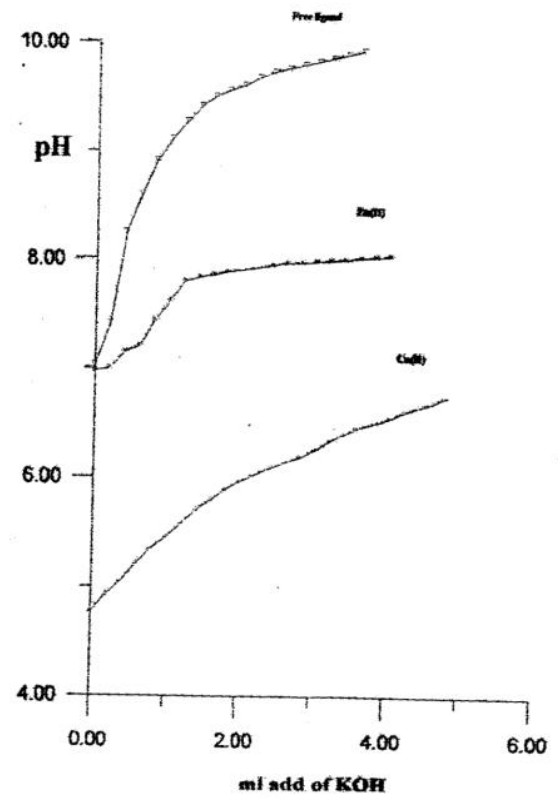

Fig.(3) pH-titration curyes, of Per and its complexes $\mathrm{Cu}(\mathrm{II})$-complex, and $\mathrm{Zn}$ (II) -complex at $\mathrm{T}=30^{\circ} \mathrm{C}$ and the ratio of (metal-ligand) $=1: 1,\left[\mathrm{KNO}_{3}\right]=0.1 \mathrm{M}$, $[$ Per $]=0.601 \mathrm{M}$ and $[\mathrm{KOH}]=0.0035 \mathrm{M}$

Table (3) Thermodynamic functions for the complexation of Per with $\mathrm{Cu}^{2+}$, and $\mathrm{Zn}^{2+}$ (1/10) methanol-water medium and $0 . \mathrm{IM} \mathrm{KNO}_{3}$ at different temperatures.

\begin{tabular}{|c|c|c|c|}
\hline $\mathrm{M}$ & $\Delta \mathrm{G}^{\mathbf{o}}$ & $\Delta \mathrm{H}^{\mathbf{o}}$ & $\Delta \mathrm{S}^{\mathbf{o}}$ \\
\hline & 6.874 & -11.2137 & -0.1113 \\
$\mathrm{Cu}(\mathrm{II})$ & 7.1469 & & -.1085 \\
& 7.5925 & & -0.1061 \\
\hline \multirow{3}{*}{$\mathrm{Zn}(\mathrm{II})$} & 4.838 & -27.7907 & -0.0617 \\
& 5.0979 & & -0.0607 \\
& 5.4203 & & -0.0600 \\
\hline
\end{tabular}

\section{Complexes of lanthanides with ligands:}

1- pH - metric study:

The lanthanide ions $\left(\mathrm{Er}^{3+}, \mathrm{Ce}^{3+}, \mathrm{Pr}^{3+}\right)$ with Per and Amin ligands $\left(1 \times 10^{-3} \mathrm{M}\right)$ were titrated against $\mathrm{KOH}$ at $\left(20,30\right.$, and $\left.40{ }^{\circ} \mathrm{C}\right)$ and ionic strength of $0.1 \mathrm{M} \mathrm{KNO}_{3}$ in methanol aqueous medium. The titration curves of the metal-ligand mixtures were 
plotted and the $\mathrm{pH}$ - reading depressed relative to that of the titration curves of the free ligand. The formation constants for (Per-Er(III) complex), (Amin- $\operatorname{Er}$ (III) complex), (Amin-Pr(III))complex and (Amin-Ce(III)) complex were determined by using the linear least- square computer program. According the average values are represented in table (4) the following general remarks can be pointed:

1- The maximum values of $\bar{n}$ was $=1$ indicating the formation of $1: 1$ (metal:ligand) complexes(4).

2- The metal titration curves indicating the large decrease in $\mathrm{pH}$ for metal titration curves relative to ligand titration curve are shown in Fig.(5).

3- The metal ions solutions used in the present study were dilute $\left(10^{-4} \mathrm{M}\right)$, hence there were no possibility of formation of polynuclear complexes(5), that agree with Fig. (6)

\section{Thermodynamic functions}

Thermodynamic parameters $\Delta \mathrm{G}^{\mathrm{o}}, \Delta \mathrm{H}^{\mathrm{o}}$ and $\Delta \mathrm{S}^{\mathrm{o}}$ for the chelate compounds were calculated from the stability constants obtained at various temperatures $(20,30$ and $40{ }^{\circ} \mathrm{C}$ ). The values of the thermodynamic parameters associated with complexes formation are indicated in tables (4), and (5). The stepwise stability constants of complexes increase with increasing the temperature. The positive values of $\Delta \mathrm{G}^{\mathrm{o}}$ for complexation process suggests the nonspontaneous nature and the negative values of $\Delta \mathrm{H}^{\mathrm{o}}$ meaning that these processes are exothermic and clearly reflect the increasing metal-ligand strength. The large negative $\Delta \mathrm{S}^{\mathrm{o}}$ values attributed to the extensive solvation of metal chelates in aqueous - methanol medium. The positive $\Delta \mathrm{S}^{\text {o }}$ values confirming that the complex formation is entropically favourable.

Table (4) Stepwise stability constants for the complexation of Amin and Per with $\mathrm{Pr}^{3+}$, $\mathrm{Ce}^{3+}$ and $\mathrm{Er}^{3+}$ in (1/10) methanol-water medium and $0.1 \mathrm{M} \mathrm{KNO}_{3}$ at different temperatures.

\begin{tabular}{|c|cc|cc|cc|}
\hline \multirow{2}{*}{$\mathrm{M}$} & \multicolumn{2}{|c|}{$293 \mathrm{~K}$} & \multicolumn{2}{c|}{$303 \mathrm{~K}$} & \multicolumn{2}{c|}{$313 \mathrm{~K}$} \\
& \multicolumn{2}{|c|}{ Log Kf } & \multicolumn{2}{|c|}{ Log Kf } & \multicolumn{2}{c|}{ Log Kf } \\
\hline \multirow{2}{*}{$\mathrm{Ce}(\mathrm{III})$} & Amin & per & \multicolumn{2}{|c|}{ Amin } & Per & \multicolumn{2}{|c|}{ Amin } & Per \\
& 6.602 & ------ & 6.6324 & ------ & 6.6628 & ------- \\
\hline Pr(III) & 6.617 & ------ & 6.601 & -------- & 6.6465 & ------- \\
\hline Er(III) & 6.5465 & 5.288 & 6.6028 & 5.458 & 6.6374 & 5.6292 \\
\hline
\end{tabular}


Table(5) Thermodynamic functions for the complexation of Per and Amin with $\mathrm{Pr}^{+3}$, $\mathrm{Ce}^{3+}$ and $\mathrm{Er}^{3+}$ in $(1 / 10)$ methanol-water medium and $0 . \mathrm{IM} \mathrm{KNO}_{3}$ at different temperatures.

\begin{tabular}{|c|ll|ll|lc|}
\hline $\mathrm{M}$ & \multicolumn{2}{|c|}{$\Delta \mathrm{G}^{\mathrm{o}}$} & \multicolumn{2}{c|}{$\Delta \mathrm{H}^{\mathrm{o}}$} & \multicolumn{2}{c|}{$\Delta \mathrm{S}^{\mathbf{o}}$} \\
\hline \multirow{3}{*}{$\mathrm{Ce}(\mathrm{III})$} & Amin & Per & Amin & Per & Amin & Per \\
& 8.8537 & ---- & -12.188 & ---- & -71.8 & ---- \\
& 9.1988 & ----- & & & -70.5 & ---- \\
& 9.544 & ---- & & & -69.4 & ---- \\
\hline \multirow{3}{*}{$\operatorname{Pr}(\mathrm{III})$} & 8.9 & ----- & 75.733 & ----- & 228 & ---- \\
& 8.9455 & ---- & & & 220.4 & ---- \\
& 9.3775 & ---- & & & 211.9 & ---- \\
\hline \multirow{3}{*}{$\operatorname{Er}(\mathrm{III})$} & 8.778 .3 & 7.0911 & $19.1934-71.5389$ & 95.4 & -0.2199 \\
& 9.155 & 7.3418 & & & 93.5 & -0.2683 \\
& 9.507 & 7.5925 & & & 91.6 & -0.2603 \\
\hline
\end{tabular}
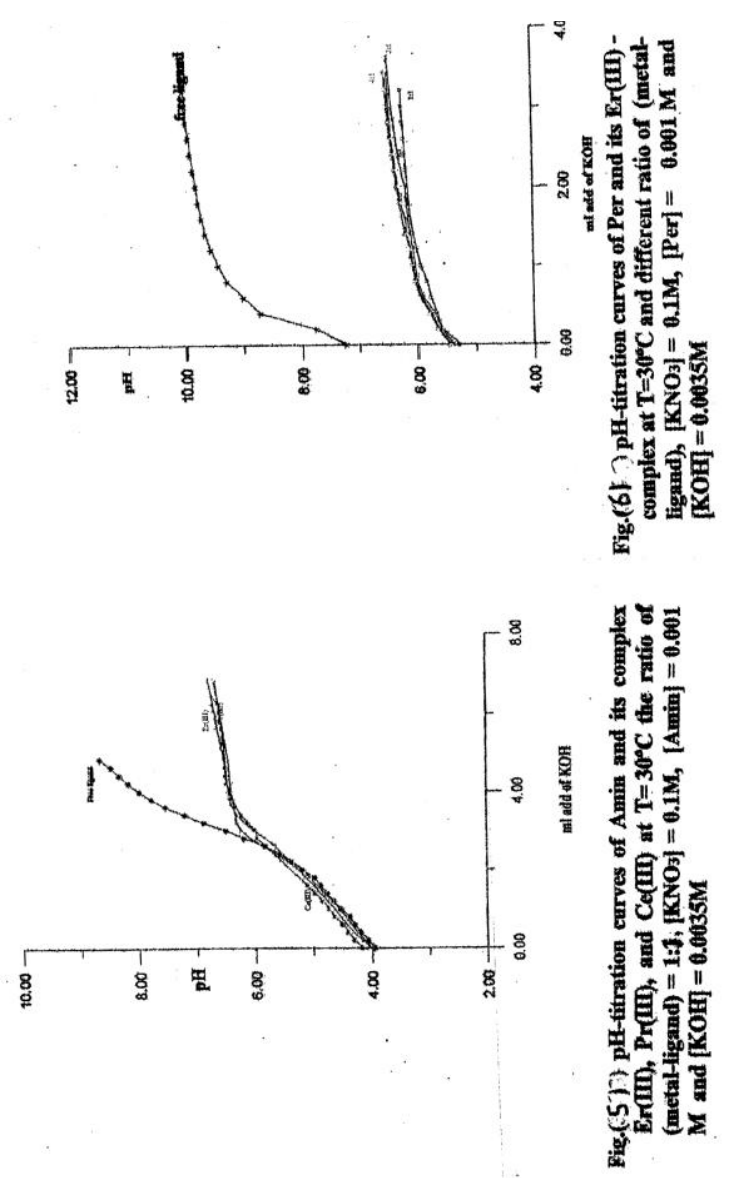


\section{References:}

1. I. Vogel. Text Book of Quantitative Inorganic Analysis, 4th ed., Longman, London, 1978.

2. Adel S. Orabi, ph.D. Thesis, Suez Canal University, Egypt (1994).

3. Hyoung - Ryun Park et al. Bull. Korean Chem. Soc., 2000, 21, 9.

4. El-Bindary A., A., El- Sonbati, A. Z., and Kera H. M., J. Chem., (1999), 77, 1305.

5. El-Bindary A., A., and El- Sonbati, A. Z., J. Chem., (2001), 49, 1312.

6. Sanyal p., Sengupta G. P., J. Ind. Chem. Soc., 67, 342, (1990).

7. Offiong E. Offiong (1998) J. Transition Met. Chem., 23, 553-555.

\section{الملخص العربى}

ان صناعة الدواء تعتبر من أهم الصناعات المؤثزة فى حياة البشر فلا غنى عن الدواء لآى منا ولكن الكن

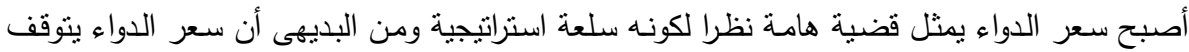

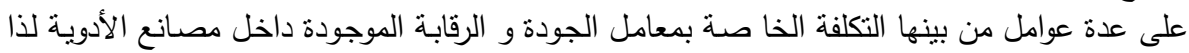

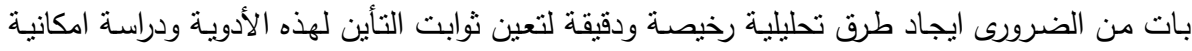

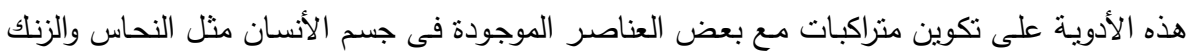

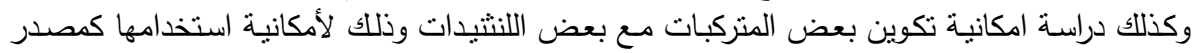
بيولوجى(biosensor) لتعرف على بعض الأنزيمات الموجودة فى الجسم وعلى هذا الأساس تم اختيار

Perlndorpil(I) and Amineptine - $\mathrm{HCl}(\mathrm{II})$ نوعين من الأدوية

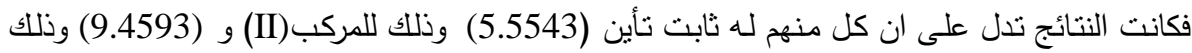

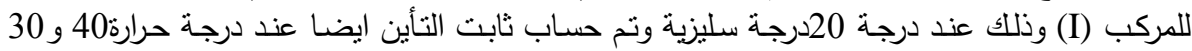

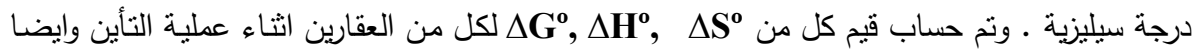

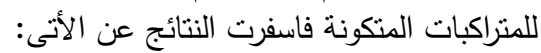

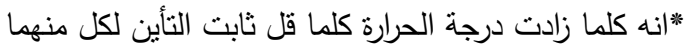

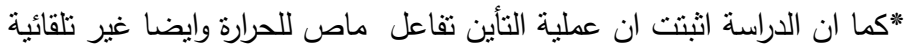

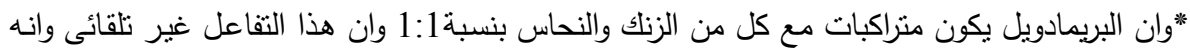
تفاعل طارد للحرارة

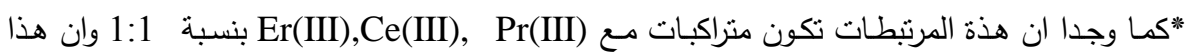

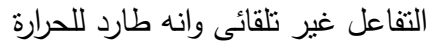
*تم حساب ثوابت التكوين لهذة المتراكبات عند درجات الحرارة 20و 30 و 40 درجة سيلزية التوصية : 1- نو صسى بان العقار (I) يؤثر على عنصر الزنك والنحاس الموجودين داخل الجسم وكذلك يمكن

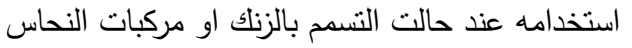

2- ان كل من العقارين يمكن استخدامهم كا (biosensor) 